\title{
Characterization of Chronic Multiclass Psychotropic Polypharmacy and Psychotherapy in Foster Care Youth in a State Medicaid Population
}

\author{
Shellie L. Keast, PharmD, PhD; Laura M. Tidmore, PharmD; Deborah Shropshire, MD;
} Nancy Nesser, PharmD, JD; and Tammy L. Lambert, PharmD, PhD

\begin{abstract}
BACKGROUND: Foster youth have higher rates of psychotropic medication use and concurrent multiclass psychotropic polypharmacy compared with nonfoster youth. However, less is known about the extent of multiclass psychotropic polypharmacy after adjusting for patient factors associated with psychotropic medication use
\end{abstract}

OBJECTIVES: To (a) compare psychotropic medication use and psychotherapy use by youth in foster care to those not in foster care in the Oklahoma Medicaid population across various sociodemographic and clinical factors, and (b) determine if patient-related characteristics are associated with high levels of concurrent multiclass psychotropic polypharmacy.

METHODS: This cross-sectional, retrospective analysis was conducted using paid prescription, outpatient, and inpatient Oklahoma Medicaid administrative claims from calendar year 2016. Foster youth and adolescents aged 20 years or younger were identified $(n=9,325)$ and compared with the general Oklahoma Medicaid population of the same age $(n=639,868)$. Descriptive statistics highlight baseline demographic and clinical differences between the 2 groups. Multivariable logistic regression was used to determine if covariates were associated with concurrent multiclass psychotropic polypharmacy. A subgroup analysis of foster youth taking at least 1 psychotropic medication was also performed to determine factors associated with the highest level of concurrent multiclass psychotropic polypharmacy.

RESULTS: Foster care was associated with higher odds of concurrent multiclass psychotropic polypharmacy regardless of presence of psychotherapy. Among the subgroup of foster youth taking at least 1 psychotropic medication, attention deficit hyperactivity disorder medications were the most commonly prescribed medication class, followed by antidepressants and anxiolytics when use was not chronic. However, at the highest level of chronic multiclass psychotropic polypharmacy (4-5 chronic concurrent medications), antipsychotics rose to the top, and anxiolytics were the least likely to be prescribed. Overall, the foster care population had the highest proportion of individuals with concurrent multiclass psychotropic polypharmacy $(9.2 \%$ vs. $1.9 \%, P<0.0001)$. The highest level of chronic multiclass psychotropic polypharmacy was more likely to occur in males $(0 R=1.66$, $95 \% \mathrm{Cl}=1.40-1.96)$ and patients living in group homes ( $0 \mathrm{R}=4.13,95 \%$ $\mathrm{Cl}=2.02-8.44)$ or foster homes $(\mathrm{OR}=1.66,95 \% \mathrm{Cl}=1.25-2.19)$. Being overweight or obese was associated with an $83 \%$ higher odds of being at the highest level of concurrent multiclass psychotropic polypharmacy $(95 \% \mathrm{Cl}=1.27-2.64)$.

CONCLUSIONS: Despite higher psychotherapy use, high rates of psychotropic medication use and concurrent multiclass psychotropic polypharmacy in foster youth remain a concern for policymakers. Patterns observed at different levels of concurrent multiclass psychotropic polypharmacy may be key to identifying youth who require additional monitoring. Future research exploring factors associated with higher levels of psychotropic concurrent multiclass psychotropic polypharmacy in foster youth can lead to actionable interventions and important policy changes.

J Manag Care Spec Pharm. 2019;25(12):1340-48

Copyright $\odot 2019$, Academy of Managed Care Pharmacy. All rights reserved.

\section{What is already known about this subject}

Foster youth are more likely to be prescribed psychotropic medications in comparison with other youth

Foster youth have higher rates of psychotropic polypharmacy. Youth in foster care have higher utilization rates of health services.

\section{What this study adds}

Increase in age, being male, increasing Deyo Charlson Comorbidity Index score, being overweight or obese, and presence of hyperlipidemia were associated with higher odds of concurrent multiclass psychotropic polypharmacy among youth.

Although foster youth receiving psychotherapy have lower odds of concurrent multiclass psychotropic polypharmacy than those not receiving psychotherapy, foster youth are still at higher odds of taking psychotropic medications compared with their nonfoster counterparts regardless of the presence of psychotherapy.

ADHD medications are most commonly prescribed when youth are taking 3 or fewer medications, and antipsychotic medications are most commonly prescribed among youth taking 4-5 medications.

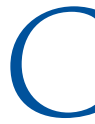
oncern about psychotropic medication use in foster youth has been well documented in the literature. Studies consistently show that foster youth use more psychotropic medication compared with other youth, including other youth on Medicaid. ${ }^{1-3}$ Foster youth also have higher rates of taking multiple psychotropic medications either within the same class or between multiple different medication classes. ${ }^{4-9}$

Foster youth are a vulnerable population at increased risk for adverse childhood experiences compared with other children, even after controlling for income and family structure..$^{10}$ Foster youth also have twice the prevalence of mental health disorders compared with nonfoster youth receiving Supplemental Security Income. ${ }^{11}$ In addition, these youth use 
mental health services at higher rates than other children. ${ }^{12}$ However, despite the prevalence of mental health issues that make this population more susceptible to psychotropic medication use and known concerns of psychotropic overprescribing among foster youth, use of these medications still occurs at high rates..$^{13,14}$

Policymakers have taken notice of the high levels of psychotropic medication use and polypharmacy among foster youth. The American Academy of Child and Adolescent Psychiatry published guidelines to promote safe use of psychotropic medications in children and adolescents. ${ }^{15}$ By 2010, 26 states had guidelines for psychotropic medication use in foster children, and 13 more had guidelines in development. ${ }^{16}$ The increase in antipsychotic prescribing for children and adolescents over recent decades has also prompted the National Committee for Quality Assurance's Healthcare Effectiveness Data and Information Set (HEDIS) to include the use of multiple concurrent antipsychotics by children and adolescents as one of their outcome measures. ${ }^{17}$ It included this measure because youth prescribed antipsychotics are at risk for weight gain, extrapyramidal side effects, hyperprolactinemia, and metabolic effects, so this measure can highlight potentially unsafe use of antipsychotic medications. ${ }^{18}$ Although these policy initiatives show promise in curbing observed upward trends in psychotropic medication use and polypharmacy among children and adolescents ${ }^{14}$ recent studies are still finding high levels of psychotropic medication use and polypharmacy among foster youth. ${ }^{8,9}$

There remains an opportunity to better understand concurrent multiclass psychotropic polypharmacy (use of at least 2 classes of psychotropic medications concurrently for at least 90 consecutive days) alongside psychotherapy and to better understand prescription patterns at various levels of psychotropic polypharmacy in this population. The primary objective of this study was to describe psychotropic medication and psychotherapy use by youth in foster care in the Oklahoma Medicaid population compared with those not in foster care. Secondary objectives were to describe the prevalence of each drug class across different levels of concurrent multiclass psychotropic polypharmacy and identify patient-related characteristics associated with the highest level of concurrent multiclass psychotropic polypharmacy.

\section{Methods}

\section{Data Source}

Data for this research used computerized, individual-level prescription, outpatient, and inpatient Oklahoma Medicaid claims and eligibility data from the Oklahoma Health Care Authority (OHCA), along with foster care eligibility data from the Oklahoma Department of Human Services (ODHS). Pharmacy Management Consultants (PMC), a department of the University of Oklahoma College of Pharmacy, maintains administrative claims data for OHCA in a secure environment. Use of the data was part of an agreement between PMC, OHCA, and ODHS.
Data were extracted and deidentified for research purposes. The institutional review boards at the University of Oklahoma Health Sciences Center and ODHS approved this study.

\section{Study Design}

Stakeholders from PMC, OHCA, and ODHS initiated this research with guidance from local practitioners and individuals involved in caring for children and adolescents in foster care. This cross-sectional, retrospective analysis of paid administrative claims was part of a larger mixed-methods project assessing the psychotropic medication use process in Oklahoma foster youth. The review period was January 1, 2016-December 31, 2016. Oklahoma Medicaid (MOK) youth were included in the review if they were eligible for MOK at any time during the review period and were aged 0-20 years (defined as a child by OHCA). Any person designated as foster care, but with unconfirmed MOK eligibility was excluded. A subgroup analysis was performed on foster youth with any use of attention deficit hyperactivity disorder (ADHD), antidepressant, antipsychotic, mood stabilizer, and/or anxiolytic medications. This subgroup was analyzed across 4 levels: nonchronic use (lowest), chronic single-class use, 2-3 classes, or 4-5 classes (highest).

\section{Outcomes}

The outcomes for this research were based on metrics adapted from the Medicaid/Mental Health Network for Evidence Based Treatment (MEDNET) collaboration. ${ }^{19}$ The metrics were designed to determine various drug or service patterns of use within the Medicaid population. The primary outcome was concurrent multiclass polypharmacy (defined as concurrent use of at least 2 different classes of medications for 90 or more consecutive days). For the subgroup analysis, the outcome of concurrent multiclass polypharmacy was divided into nonchronic use (lowest), chronic single-class use, 2-3 concurrent classes, or 4-5 concurrent classes (highest).

The classes of psychotropic medications selected for review were identified by a Generic Product Identifier ${ }^{20}$ and included ADHD, anti-anxiety, depression, first- and second-generation antipsychotics, and mood stabilizers. ADHD medications included amphetamines salts, clonidine, guanfacine, atomoxetine, methylphenidate, and dexmethylphenidate. Anxiolytic medications included benzodiazepines, hydroxyzine, and buspirone. Antidepressant medications included selective serotonin reuptake inhibitors, tricyclic antidepressants, serotonin and norepinephrine reuptake inhibitors, mirtazapine, doxepin, trazodone, and bupropion. As stated, antipsychotics included all first- and second-generation products. Mood stabilizers included valproic acid, carbamazepine, lamotrigine, oxcarbazepine, and lithium.

\section{Covariates}

Covariates were determined using the Andersen framework for health care utilization. ${ }^{21}$ This framework is used to understand 


\section{FIGURE 1 Inclusion and Exclusion Flowchart}

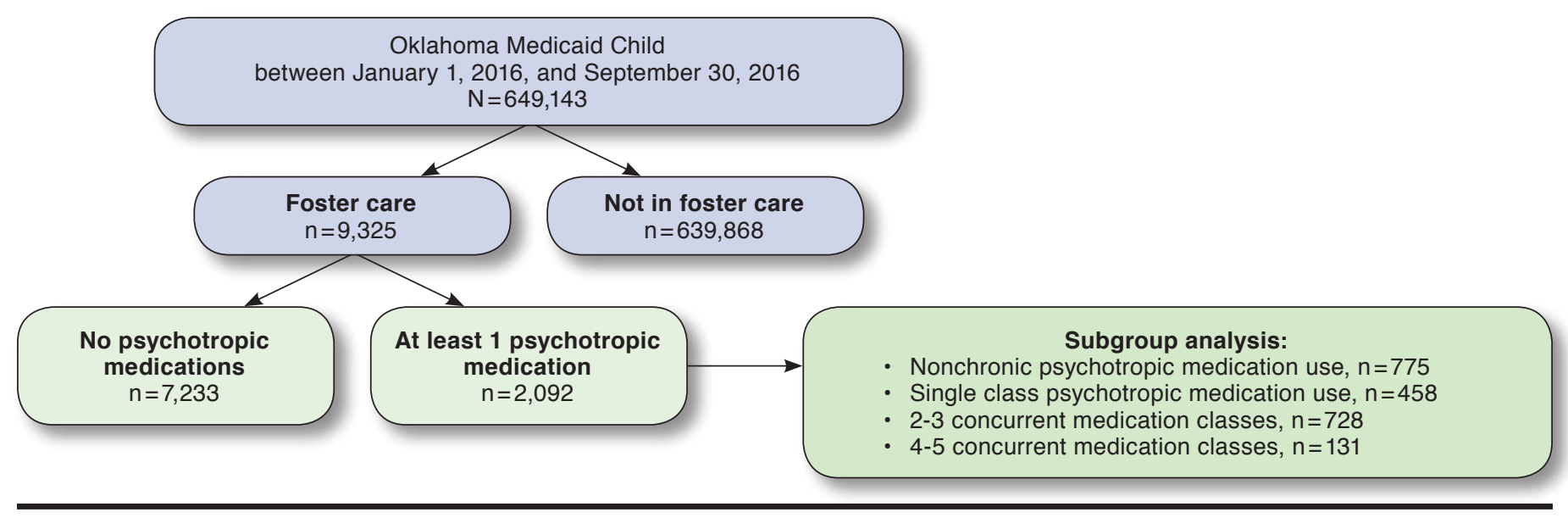

health care utilization at several levels of determinants of health. The 3 levels assessed in this study were predisposing factors, enabling factors, and need factors.

Predisposing factors included were age (calculated as age on the last day of the review period); sex (male or female); selfreported race; and length of MOK eligibility during the review year (in months). Subjects who reported more than 1 race were combined into a single classification for multiple races. Marital status and occupation were not assessed given the age of the population. Education level was not included in the data available for the study.

Core-based statistical area (CBSA) designation served as an enabling factor because disparities in access to health care exist between rural and urban areas. ${ }^{22}$ Counties are classified as rural, micropolitan, or metropolitan based on their population size as of the 2010 census. ${ }^{23}$ The CBSA designation covariate was split into rural versus micropolitan and metropolitan.

Clinical characteristics and psychotherapy served as need factors. Those included were presence of a mental healthrelated diagnosis, psychotherapy, Deyo Charlson Comorbidity Index (DCCI) score, ${ }^{24}$ having overweight or obese status, hyperlipidemia, opioid dependence, and nonopioid substance abuse. International Classification of Diseases, Tenth Revision, Clinical Modification (ICD-10-CM) diagnosis codes within the claims data served as identifiers for presence of hyperlipidemia (E78.5). The variable for body mass index was recoded as a dummy variable, where overweight or obese status $=1$ based on the presence of ICD-10-CM diagnosis codes for overweight or obesity (E66.x). DCCI score is derived from an algorithm of diagnosis codes and a higher comorbidity index correlates to more comorbidities. ${ }^{25}$ The mental health services codes used to define psychotherapy were determined by the collaborative research team (available from the authors upon request).

\section{Statistical Analysis}

Descriptive statistics were calculated using chi-square, Fisher's exact, or Student's t-tests (where appropriate) to assess baseline demographic and clinical differences between foster youth and Medicaid youth not in foster care. Multivariable logistic regression was used to determine if the collected covariates were factors associated with concurrent multiclass psychotropic polypharmacy. Ordered logistic regression was used to analyze the subgroup of the foster care population that had received at least 1 claim for a psychotropic medication to determine whether covariates were associated with having a higher level of polypharmacy. All analyses were performed using SAS version 9.4 (SAS Institute, Cary, NC).

\section{Results}

From January 1, 2016, to December 31, 2016, a total of 649,193 Oklahoma Medicaid youth were identified as eligible for this study. Of those, 9,481 were identified as in foster care. After applying exclusions, 639,868 nonfoster and 9,325 foster care members remained (Figure 1). Table 1 highlights the demographics of these 2 groups. Compared with the nonfoster youth, the foster care population was younger (6.4 years vs. 8.7 years, $P<0.001$ ), with most youth aged less than 4 years. A larger proportion of foster care youth self-identified with multiple races compared with the general population (22.8\% vs. $15.9 \%, P<0.001)$. The foster care population maintained a longer average period of eligibility (10.9 months vs. 9.9 months, $P<0.001$ ). Based on utilization data, foster youth had a higher proportion of overall prescription medication use than the general population $(77.9 \%$ vs. $62.4 \%, P<0.001)$, as well as higher use of psychotropic medications ( $22.4 \%$ vs. $10.6 \%, P<0.001$ ). Although medical claims were high in both populations, nearly 


\begin{tabular}{|c|c|c|c|c|}
\hline \multirow[b]{2}{*}{ Age, mean (SD) } & $\begin{array}{c}\text { Nonfoster }^{\mathrm{a}} \\
(\mathrm{n}=639,868)\end{array}$ & \multicolumn{2}{|c|}{$\begin{array}{c}\text { Foster }^{\mathrm{a}} \\
(\mathrm{n}=9,325)\end{array}$} & \multirow{2}{*}{$\frac{P \text { Value }}{<0.001}$} \\
\hline & $(5.72)$ & 6.41 & $(5.00)$ & \\
\hline \multicolumn{5}{|l|}{ Age group, years } \\
\hline $0-4$ & $29.2(186,691)$ & 43.9 & $(4,090)$ & \multirow{3}{*}{$<0.001$} \\
\hline $5-12$ & $41.6(266,011)$ & 40.8 & $(3,802)$ & \\
\hline $13-20$ & $29.3(187,166)$ & 15.4 & $(1,433)$ & \\
\hline Sex (male) & $50.5(323,229)$ & 52.1 & $(4,857)$ & 0.003 \\
\hline \multicolumn{5}{|l|}{ Race } \\
\hline White & $59.6(381,237)$ & 55.2 & $(5,150)$ & \multirow{7}{*}{$<0.001$} \\
\hline Black & $11.2 \quad(71,532)$ & 12.0 & $(1,122)$ & \\
\hline Asian & $1.5 \quad(9,542)$ & 0.2 & (15) & \\
\hline American Indian or Alaskan Native & $11.5 \quad(73,475)$ & 9.7 & $(904)$ & \\
\hline Native Hawaiian or Pacific Islander & $0.4 \quad(2,420)$ & $0.1^{\mathrm{b}}$ & & \\
\hline Mixed & $15.9(101,592)$ & 22.8 & $(2,124)$ & \\
\hline Unknown & $0.1 \quad(70)$ & $0.0^{\mathrm{b}}$ & & \\
\hline \multicolumn{5}{|l|}{ CBSA designation } \\
\hline Rural & $16.3(104,546)$ & 16.2 & $(1,508)$ & \multirow{3}{*}{0.333} \\
\hline Metro or micro & $82.4(527,001)$ & 83.8 & $(7,813)$ & \\
\hline Unknown & $1.3 \quad(8,321)$ & $0.04^{b}$ & & \\
\hline DCCI score, mean (SD) & $0.07 \quad(0.29)$ & 0.10 & $(0.34)$ & $<0.001$ \\
\hline Overweight/obese & $2.0 \quad(12,641)$ & 2.2 & $(203)$ & 0.167 \\
\hline Hyperlipidemia & $0.4 \quad(2,284)$ & 0.3 & $(26)$ & 0.208 \\
\hline Mean months eligible, mean (SD) & $9.89 \quad(3.4)$ & 10.88 & $(2.5)$ & $<0.001$ \\
\hline Receiving any prescription medication & $62.4(399,206)$ & 77.9 & $(7,264)$ & $<0.001$ \\
\hline Received any psychotropic medication & $10.6 \quad(67,886)$ & 22.4 & $(2,092)$ & $<0.001$ \\
\hline ADHD & $6.6 \quad(42,317)$ & 16.9 & $(1,576)$ & \multirow{5}{*}{$<0.001$} \\
\hline Antipsychotics & $1.7 \quad(10,724)$ & 8.7 & $(808)$ & \\
\hline Depression & $4.2 \quad(26,998)$ & 11.9 & $(1,113)$ & \\
\hline Mood & $1.1 \quad(6,829)$ & 4.8 & $(451)$ & \\
\hline Anxiolytics & $2.6 \quad(16,502)$ & 4.64 & $(433)$ & \\
\hline \multicolumn{5}{|l|}{ Single-class polypharmacyc } \\
\hline ADHD & $1.4 \quad(8,704)$ & 5.3 & $(492)$ & \multirow{5}{*}{$<0.001$} \\
\hline Antipsychotics & $(297)$ & 0.3 & $(32)$ & \\
\hline Depression & $0.3 \quad(2,198)$ & 1.9 & $(174)$ & \\
\hline Mood & $(208)$ & 0.2 & $(20)$ & \\
\hline Anxiolytics & $(89)$ & $0.0^{\mathrm{b}}$ & & \\
\hline Concurrent multiclass psychotropic polypharmacy ${ }^{\mathrm{d}}$ & $1.9 \quad(12,394)$ & 9.2 & $(859)$ & $<0.001$ \\
\hline Two classes & $1.3 \quad(8,010)$ & 4.5 & $(418)$ & \multirow{4}{*}{$<0.001$} \\
\hline Three classes & $0.5 \quad(3,366)$ & 3.3 & $(310)$ & \\
\hline Four classes & $0.1 \quad(897)$ & 1.3 & $(121)$ & \\
\hline Five or more classes & $(121)$ & 0.1 & $(10)$ & \\
\hline Presence of psychotherapy & $4.0 \quad(25,498)$ & 22.4 & $(2,086)$ & $<0.001$ \\
\hline
\end{tabular}

aAll values are \% (n) unless otherwise indicated.

${ }^{b}$ Cell counts with less than 10 individuals were suppressed to protect patient privacy.

'One or more of the same class of medications on the same day for 90 consecutive days or longer.

dOne or more classes of mental health medications on the same day for 90 consecutive days or longer.

$A D H D=$ attention deficit hyperactivity disorder; $C B S A=$ core-based statistical area; $D C C I=$ Deyo Charlson Comorbidity Index; $S D=$ standard deviation

all foster youth had at least 1 medical claim $(97.7 \%$ vs. $71.6 \%$, $P<0.001)$. While the presence of chronic conditions was low for both populations, the foster care population had a higher DCCI score (0.10 vs. 0.07, $P<0.001)$. However, this difference may not be clinically significant. There were no significant differences in occurrence of opioid dependence, occurrence of nonopioid substance abuse, presence of hyperlipidemia, or being overweight/obese between the 2 groups. 


\begin{tabular}{|c|c|c|c|}
\hline \multirow{3}{*}{$\begin{array}{l}\text { Effect } \\
\text { Age, years }\end{array}$} & \multirow{3}{*}{$\begin{array}{r}\text { rsus G } \\
\begin{array}{r}\text { Odds } \\
\text { Ratio }\end{array} \\
1.15^{\mathrm{a}}\end{array}$} & $\begin{array}{l}\text { oncu } \\
\text { olyp } \\
\text { ral P }\end{array}$ & $\begin{array}{l}\text { acy: } \\
\text { ation }\end{array}$ \\
\hline & & \multicolumn{2}{|c|}{$95 \% \mathrm{CI}$} \\
\hline & & 1.14 & 1.15 \\
\hline Male (reference $=$ female) & $1.89^{\mathrm{a}}$ & 1.82 & 1.96 \\
\hline $\begin{array}{l}\text { American Indian or Alaskan Native } \\
\text { (reference = white) }\end{array}$ & $0.71^{\mathrm{a}}$ & 0.66 & 0.75 \\
\hline Asian (reference = white) & $0.19^{\mathrm{a}}$ & 0.13 & 0.27 \\
\hline Black (reference $=$ white) & $0.56^{\mathrm{a}}$ & 0.52 & 0.59 \\
\hline Mixed (reference $=$ white) & $0.84^{a}$ & 0.79 & 0.90 \\
\hline $\begin{array}{l}\text { Native Hawaiian or Pacific Island } \\
\text { (reference=white) }\end{array}$ & $0.42^{\mathrm{a}}$ & 0.26 & 0.68 \\
\hline Rural (reference = urban) & $0.89^{a}$ & 0.84 & 0.93 \\
\hline DCCI score, mean & $1.42^{\mathrm{a}}$ & 1.36 & 1.48 \\
\hline Presence of overweight/obesity & $1.50^{\mathrm{a}}$ & 1.37 & 1.64 \\
\hline Presence of hyperlipidemia & $1.73^{\mathrm{a}}$ & 1.45 & 2.07 \\
\hline $\begin{array}{l}\text { Foster care vs. nonfoster care receiving } \\
\text { no psychotherapy }\end{array}$ & $5.81^{\mathrm{a}}$ & 5.18 & 6.52 \\
\hline $\begin{array}{l}\text { Foster care vs. nonfoster care receiving } \\
\text { psychotherapy }\end{array}$ & $2.22^{\mathrm{a}}$ & 1.99 & 2.48 \\
\hline
\end{tabular}

While ADHD medications were the most commonly prescribed class of psychotropic medication regardless of foster care status, more foster youth received a medication from this class compared with youth not in foster care $(16.9 \%$ vs. $6.6 \%$, $P<0.001)$. Similarly, of youth meeting criteria for single-class polypharmacy, ADHD medications were the most frequently prescribed drug class in both populations, but more foster youth received these medications than youth not in foster care (5.3\% vs. $1.4 \%, P<0.001$ ). Polypharmacy was also significantly higher for foster youth in each of the medication classes except anxiolytics $(P<0.001$ for antipsychotics, depression, and mood classes). In addition, overall presence of concurrent multiclass psychotropic polypharmacy was higher in foster youth compared with the general population $(9.2 \%$ vs. $1.9 \%, P<0.001)$. Psychotherapy in foster youth was higher than the general population $(22.4 \%$ vs. $4.0 \%, P<0.001$ ). Furthermore, the percentage of foster youth using each type of service was also higher than observed in the nonfoster group $(P<0.001$ for all), with psychotherapy being substantially higher in foster youth (22.4\% vs. $4.0 \%)$.

Several patient factors were associated with increased odds of having concurrent multiclass psychotropic polypharmacy after adjusting for covariates (Table 2). Each increase in 1 year of age was associated with a $14.5 \%$ higher odds of concurrent multiclass psychotropic polypharmacy (odds ratio $[\mathrm{OR}]=1.15$, 95\% confidence interval $[\mathrm{CI}]=1.14-1.15)$ as was being male $(\mathrm{OR}=1.89,95 \% \mathrm{CI}=1.82-1.96)$. Being any race other than white or living in a rural location $(\mathrm{OR}=0.89,95 \% \mathrm{CI}=0.84-0.93)$ was associated with lower odds of psychotropic polypharmacy. The clinical characteristics of being overweight or obese ( $\mathrm{OR}=1.50,95 \% \mathrm{CI}=1.37-1.64)$, having hyperlipidemia $(\mathrm{OR}=1.73,95 \% \mathrm{CI}=1.45-2.07)$, and each increase in 1 point in DCCI score (OR $=1.42,95 \% \mathrm{CI}=1.36-1.48)$ were associated with increased odds of psychotropic polypharmacy.

Given an interaction between foster care status and psychotherapy, individuals in foster care receiving no psychotherapy had higher odds of polypharmacy than individuals not in foster care receiving no psychotherapy (OR=5.81, 95\% $\mathrm{CI}=5.18-6.52$; Table 2). In addition, individuals in foster care receiving psychotherapy had higher odds of polypharmacy than those not in foster care receiving psychotherapy $(\mathrm{OR}=2.22,95 \% \mathrm{CI}=1.99-2.48)$.

Demographics of a subgroup analysis of foster youth taking any targeted psychotropic medication are highlighted in Table 3. Those in the highest level of multiclass use (4-5 chronic psychotropic medications) had a mean age of 13.1 years, whereas single class chronic use had the lowest mean age (9.3 years). No youth aged 4 years or younger were prescribed medications in the highest level (4-5 chronic psychotropic medications). The proportion of males and whites increased from the lowest to the highest level of use (53.7\%-71.0\% and 51.0\%-65.7\%). A higher proportion of those in the $4-5$ chronic psychotropic medication classes subgroup were classified as being overweight/obese $(12.2 \%, P<0.001)$ and having hyperlipidemia $(3.1 \%, P=0.004)$ compared with those in the other levels of chronic psychotropic polypharmacy. ADHD was the most commonly prescribed medication class for those with nonchronic use to those taking 2-3 chronic psychotropic medications. However, antipsychotics were the most commonly prescribed medication class among those taking 4-5 concurrent psychotropic medications.

Controlling for independent variables, the odds of the highest level of multiclass chronic psychotropic polypharmacy (4-5 medication classes) compared with lower levels of polypharmacy was 2.1 times greater for those with psychotherapy than for those with no psychotherapy (95\% CI = 1.80-2.49; Table 4). High-level chronic psychotropic use was also more likely in males ( $\mathrm{OR}=1.66,95 \% \mathrm{CI}=1.40-1.96)$. Being overweight or obese was associated with an $83 \%$ higher odds of the highest level of concurrent multiclass psychotropic polypharmacy compared with those who were not overweight or obese (95\% $\mathrm{CI}=1.27-2.64)$. Compared with living in their own residence, living in a foster home, a group home, or other type of home were all associated with the highest level of concurrent multiclass psychotropic polypharmacy. High-level psychotropic use was not associated with presence of hyperlipidemia, an increased DCCI score, black race, mixed race, or rural location. 


\begin{tabular}{|c|c|c|c|c|c|c|c|c|c|}
\hline \multirow[b]{2}{*}{ Age, mean (SD) } & \multicolumn{2}{|c|}{$\begin{array}{c}\text { Nonchronic } \\
\text { Psychotropic } \\
\text { Medication Use } \\
(\mathbf{n}=775)\end{array}$} & \multicolumn{2}{|c|}{$\begin{array}{c}\text { Single-Class Chronic } \\
\text { Psychotropic } \\
\text { Medication Use } \\
(\mathbf{n}=458)\end{array}$} & \multicolumn{2}{|c|}{$\begin{array}{c}2-3 \text { Chronic } \\
\text { Psychotropic } \\
\text { Medication Classes } \\
(\mathrm{n}=728) \\
\end{array}$} & \multicolumn{2}{|c|}{$\begin{array}{c}\text { 4-5 Chronic } \\
\text { Psychotropic } \\
\text { Medication Classes } \\
(\mathrm{n}=131)\end{array}$} & \multirow{2}{*}{$\frac{P \text { Value }}{<0.001}$} \\
\hline & 10.15 & $(4.53)$ & 9.29 & (3.58) & 11.74 & (3.34) & 13.13 & $(2.89)$ & \\
\hline \multicolumn{9}{|l|}{ Age group, years } & $<0.001$ \\
\hline $0-4$ & 11.4 & (88) & 4.8 & (22) & $0.3^{c}$ & & $0.0^{\mathrm{c}}$ & & \\
\hline $5-12$ & 53.9 & (418) & 74.0 & (339) & 57.2 & (416) & 35.9 & $(47)$ & \\
\hline $13-20$ & 34.7 & $(269)$ & 21.2 & $(97)$ & 42.6 & $(310)$ & 64.1 & $(84)$ & \\
\hline Sex (male) & 53.7 & (416) & 62.2 & $(285)$ & 60.2 & $(438)$ & 71.0 & (93) & 0.001 \\
\hline \multicolumn{9}{|l|}{ Race } & 0.003 \\
\hline White & 51.0 & (395) & 51.8 & $(237)$ & 56.3 & $(410)$ & 65.7 & (86) & \\
\hline Black & 12.4 & (96) & 9.6 & (44) & 12.8 & (93) & 9.9 & (18) & \\
\hline American Indian or Alaskan Native & 10.3 & $(80)$ & 8.5 & (39) & 5.4 & (39) & $4.6^{\mathrm{c}}$ & & \\
\hline Mixed & 26.1 & $(202)$ & 29.5 & $(135)$ & 24.7 & $(180)$ & 19.9 & $(86)$ & \\
\hline Unknown ${ }^{\mathrm{b}, \mathrm{c}}$ & $0.3^{\mathrm{c}}$ & & $0.7 \mathrm{c}$ & & $0.8^{\mathrm{c}}$ & & $0.0^{c}$ & & \\
\hline Rural & 16.1 & $(125)$ & 14.2 & $(65)$ & 16.1 & $(117)$ & 10.7 & (14) & 0.345 \\
\hline Mean months eligible, mean (SD) & 11.55 & $(1.51)$ & 11.88 & $(0.68)$ & 11.91 & $(0.64)$ & 11.98 & $(0.15)$ & $<0.001$ \\
\hline Receiving psychotherapy & 36.5 & $(283)$ & 48.0 & $(220)$ & 61.4 & $(447)$ & 53.4 & (70) & $<0.001$ \\
\hline \multicolumn{9}{|l|}{ Residence status } & $<0.001$ \\
\hline Own residence & 14.2 & (110) & 49.7 & (53) & 0.4 & $(62)$ & $35.7 \mathrm{c}$ & & \\
\hline Foster home & 49.7 & $(385)$ & 50.2 & $(230)$ & 51.1 & $(372)$ & 45.8 & $(60)$ & \\
\hline Group home & $0.4^{\mathrm{c}}$ & & $1.3^{\mathrm{c}}$ & & 2.5 & (18) & $3.8^{\mathrm{c}}$ & & \\
\hline Other & 35.7 & $(277)$ & 36.9 & (169) & 37.9 & $(276)$ & 45.0 & (59) & \\
\hline Overweight/obese & 4.1 & $(32)$ & 2.4 & (11) & 7.3 & (53) & 12.2 & (16) & $<0.001$ \\
\hline Hyperlipidemia & $0.7^{\mathrm{c}}$ & & $0.2^{\mathrm{c}}$ & & $0.8^{\mathrm{c}}$ & & $3.1^{\mathrm{c}}$ & & 0.004 \\
\hline DCCI score, mean (SD) & 0.12 & $(0.37)$ & 0.13 & $(0.46)$ & 0.11 & $(0.34)$ & 0.11 & $(0.38)$ & 0.508 \\
\hline \multicolumn{10}{|l|}{ Medication utilization } \\
\hline ADHD & 57.7 & $(447)$ & 81.4 & (373) & 86.1 & $(627)$ & 98.5 & (129) & $<0.001$ \\
\hline Antipsychotic & 17.3 & (134) & 10.7 & $(49)$ & 68.0 & $(495)$ & 99.2 & $(130)$ & $<0.001$ \\
\hline Antidepressant & 39.6 & $(307)$ & 26.0 & (119) & 76.9 & $(560)$ & 97.0 & $(127)$ & $<0.001$ \\
\hline Mood stabilizer & 12.0 & (93) & 6.1 & (28) & 30.4 & (221) & 83.2 & (109) & $<0.001$ \\
\hline Anxiolytic & 24.0 & $(186)$ & 10.7 & (49) & 19.2 & $(140)$ & 44.3 & $(58)$ & $<0.001$ \\
\hline
\end{tabular}

a All values are $\%(n)$ unless otherwise indicated.

${ }^{b}$ The 11 members of unknown race were excluded from the final regression model (Table 4).

${ }^{c} C e l l$ counts with less than 10 individuals were suppressed to protect patient privacy.

$A D H D=$ attention deficit hyperactivity disorder; $D C C I=$ Deyo Charlson Comorbidity Index; $S D=$ standard deviation

\section{Discussion}

\section{Implications}

This study compared psychotropic medication use and psychotherapy occurrence for foster care youth versus youth not in foster care in a state Medicaid population and observed differences in concurrent multiclass psychotropic polypharmacy among foster youth versus nonfoster youth, such as increase in age, being male, increase in DCCI score, being overweight or obese, and having hyperlipidemia. However, being any race other than white and living in a rural location were associated with lower odds of concurrent multiclass psychotropic polypharmacy. Oklahoma foster youth have higher proportions of psychotherapy than youth in the general Oklahoma Medicaid population, which is similar to findings by researchers examining
Delaware's Medicaid program. ${ }^{26}$ However, Oklahoma foster youth also have a higher proportion of psychotropic medication use and a higher odds of concurrent multiclass psychotropic polypharmacy compared with youth in the general Oklahoma Medicaid population regardless of psychotherapy. Therefore, opportunities remain to better understand factors involved in psychotropic medication prescribing for foster youth.

Adverse effects are a concern with long-term use of antipsychotic medications, especially in foster youth. ${ }^{27-29}$ Oklahoma foster youth had a slightly higher DCCI score, and after adjusting for other covariates, metabolic variables such as being overweight or obese and hyperlipidemia were associated with a higher odds of concurrent multiclass psychotropic polypharmacy in foster youth compared with nonfoster youth. 


\begin{tabular}{|c|c|c|c|}
\hline \multirow{3}{*}{$\begin{array}{l}\text { Effect } \\
\begin{array}{l}\text { Presence of psychotherapy } \\
\text { (reference= none) }\end{array}\end{array}$} & \multirow{3}{*}{$\begin{array}{l}\begin{array}{l}\text { Odds } \\
\text { Ratio }\end{array} \\
2.12^{\mathrm{a}}\end{array}$} & $\begin{array}{l}\text { est L } \\
\text { chotr } \\
\text { ation }\end{array}$ & $\begin{array}{l}\text { of } \\
\text { sses) }\end{array}$ \\
\hline & & \multicolumn{2}{|c|}{$95 \% \mathrm{CI}$} \\
\hline & & 1.80 & 2.49 \\
\hline Age, years & $1.11^{\mathrm{a}}$ & 1.09 & 1.13 \\
\hline Male (reference $=$ female) & $1.66^{\mathrm{a}}$ & 1.40 & 1.96 \\
\hline $\begin{array}{l}\text { American Indian or Alaskan Native } \\
\text { (reference = white) }\end{array}$ & $0.58^{a}$ & 0.42 & 0.79 \\
\hline Black (reference = white) & 0.79 & 0.61 & 1.02 \\
\hline Mixed (reference $=$ white $)$ & 0.84 & 0.69 & 1.01 \\
\hline Rural (reference = urban) & 1.00 & 0.79 & 1.25 \\
\hline Foster home (reference $=$ own residence) & $1.66^{\mathrm{a}}$ & 1.25 & 2.19 \\
\hline Group home (reference= own residence) & $4.13^{\mathrm{a}}$ & 2.02 & 8.44 \\
\hline Other (reference = own residence) & $1.77^{\mathrm{a}}$ & 1.33 & 2.36 \\
\hline $\begin{array}{l}\text { Overweight/obese (reference }=\text { not } \\
\text { overweight or obese) }\end{array}$ & $1.83^{a}$ & 1.27 & 2.64 \\
\hline $\begin{array}{l}\text { Presence of hyperlipidemia } \\
\text { (reference =none) }\end{array}$ & 2.52 & 0.99 & 6.40 \\
\hline DCCI, mean & 0.92 & 0.74 & 1.14 \\
\hline
\end{tabular}

Therefore, metabolic monitoring of youth taking psychotropic medications, as Oklahoma Medicaid policy requires, ${ }^{30}$ should continue. However, data in this study did not allow for examination of the extent of metabolic monitoring in this population.

Results of this study indicate that foster youth are still more likely to receive psychotropic medications than their nonfoster counterparts. Higher psychotropic medication use was observed in individuals in foster care compared with those not in foster care. Although psychotherapy plays a role in lessening the odds associated with psychotropic medications, foster youth are still at a higher odds of taking psychotropics compared with their nonfoster counterparts regardless of whether they are receiving psychotherapy.

The most common medication class to be present at up to 2-3 chronic psychotropic medication class level is ADHD. However, for those taking 4-5 medication classes, antipsychotics become the highest occuring medication. ADHD medications have previously been identified as the most common drug class at various levels of psychotropic polypharmacy among Medicaid youth., ${ }^{5,9,31}$ However, less is known about which medication is most commonly prescribed at various levels of polypharmacy within a cohort of only foster youth. Zito et al. (2008) reported a similar trend of ADHD being the most commonly prescribed medication class at lower levels of multiclass polypharmacy, with antipsychotic medications being most common at the highest level..$^{32}$ Over 10 years later, in a different Medicaid population, our study found a similar pattern. Recently, Moran et al. (2019) found that approximately 1 in
660 adolescents are at risk of new-onset psychosis after receiving a prescription for an ADHD medication. ${ }^{33}$ Prescription of antipsychotic medications after initiation of ADHD medications may be a potential point to identify foster youth who may require monitoring or therapeutic interventions.

Another key finding in this study was the observation that no youth aged 4 years and younger had been prescribed medications at the highest level of concurrent multiclass psychotropic polypharmacy. Since 2010, the Oklahoma Medicaid program has used a pediatric psychiatric consultation service and prior authorization program for antipsychotics for youth aged 4 years and younger. ${ }^{34}$ This program requires all antipsychotic prescriptions for youth in this age range to be reviewed by a pediatric psychiatrist before approval. The psychiatrist service is also available for prescribers to consult with regarding any treatment regimens for pediatric Medicaid patients. This program may be an important reason for the low rate of polypharmacy in this population. It is also important to note that foster care youth had a higher percentage of children aged 4 years and under compared with the full Medicaid population (43.9\% vs. 29.2\%). This difference may have affected the results.

\section{Limitations}

This study has some limitations to consider. Administrative claims data are limited to the available information. Errors may include incorrect diagnoses or procedure codes, incorrect days supply, or inclusion of reversed claims. Prescriptions paid for out of pocket are also not reflected in data, although occurrence of this is thought to be minimal, since prescriptions for youth in this population do not have a copay or a limit on total monthly prescriptions. Also, relevant diagnosis and procedure codes included for consideration in the analysis were determined based on the clinical experience of the research team and stakeholders. Coding patterns may differ between states or regions. Coding for obesity may be underreported, particularly in younger children; therefore, obesity rates may be higher than reported.

Some variables in the administrative claims data are subject to self-reporting (e.g., race). Although coding used to determine appropriate service use was chosen by the stakeholder committee, it is possible that some service types were not included, and individuals may have received appropriate services but were not classified as such. Potential coding errors may also have been present within the analyses.

This review was limited largely to administrative claims data available through OHCA. Data were not reviewed longitudinally, which may have highlighted specific trends in psychotropic medication use. Some information, such as an individual's time in foster care, was unavailable in the claims data for inclusion in the analysis. Medicaid programs are also different from state to state, so caution should be taken in generalizing findings to other foster children or Medicaid programs. 


\section{Conclusions}

Determining appropriate psychotropic medication use in this population is challenging. Despite higher psychotherapy occurrence, rates of psychotropic medication use and concurrent multiclass psychotropic polypharmacy remain a concern in foster youth, and metabolic adverse effects were observed in this population. The ability to locate those at highest risk for high levels of psychotropic medication use in a timely fashion is key to ensuring that this population is receiving optimal care. Based on the presence of an antipsychotic at the highest level of polypharmacy, the addition of an antipsychotic to a regimen may be an important signal for additional monitoring. Longitudinal studies should be undertaken to explore factors associated with higher levels of psychotropic polypharmacy in foster youth and used to further assist in developing actionable interventions. Outcomes of multiclass psychotropic polypharmacy in foster youth, such as metabolic diseases, placement issues, and issues when foster kids age out of the system, should also be explored to further inform potential opportunities for policies.

\section{Authors}

SHELLIE L. KEAST, PharmD, PhD; LAURA M. TIDMORE, PharmD; and TAMMY L. LAMBERT, PharmD, PhD, University of Oklahoma College of Pharmacy and Pharmacy Management Consultants, Oklahoma City, Oklahoma. DEBORAH SHROPSHIRE, MD, Oklahoma Department of Human Services, Oklahoma City, and NANCY NESSER, PharmD, JD, Oklahoma Health Care Authority, Oklahoma City.

AUTHOR CORRESPONDENCE: Shellie L. Keast, PharmD, PhD, Assistant Professor, University of Oklahoma College of Pharmacy, 1110 N. Stonewall Ave., Oklahoma City, OK 73117.

Tel.: 405.271.6878 x32412; E-mail: Shellie-Keast@ouhsc.edu.

\section{REFERENCES}

1. Rubin D, Matone M, Huang Y, et al. Interstate variation in trends of psychotropic medication use among medicaid-enrolled children in foster care. Child Youth Serv Rev. 2012;34(8):1492-99. Available: https://www.sciencedirect.com/science/article/pii/S0190740912001648?via\%3Dihub. Accessed October 15, 2019.

2. Pathak P, West D, Martin BC, Helm ME, Henderson C. Evidence-based use of second-generation antipsychotics in a state Medicaid pediatric population, 2001-2005. Psychiatr Serv. 2010;61(2):123-29. Available at: https:// ps.psychiatryonline.org/doi/full/10.1176/ps.2010.61.2.123. Accessed October 15, 2019

3. Patten SB, Waheed W, Bresee L. A review of pharmacoepidemiologic studies of antipsychotic use in children and adolescents. Can J Psychiatry. 2012;57(12):717-21. Available at: https://journals.sagepub.com/ doi/10.1177/070674371205701202. Accessed October 15, 2019.

4. DosReis S, Zito JM, Safer DJ, Gardner JF, Puccia KB, Owens PL. Multiple psychotropic medication use for youths: a two-state comparison. J Child Adolesc Psychopharmacol. 2005;15(1):68-77.

5. Fontanella CA, Warner LA, Phillips GS, Bridge JA, Campo JV. Trends in psychotropic polypharmacy among youths enrolled in Ohio Medicaid, 2002-2008. Psychiatr Serv. 2014;65(11):1332-40. Available at: https:// ps.psychiatryonline.org/doi/full/10.1176/appi.ps.201300410. Accessed October 15, 2019

6. Kamble P, Chen H, Johnson ML, Bhatara V, Aparasu RR. Concurrent use of stimulants and second-generation antipsychotics among children with ADHD enrolled in Medicaid. Psychiatr Serv. 2015;66(4):404-10. Available at: https://ps.psychiatryonline.org/doi/full/10.1176/appi.ps.201300391?url_ ver=Z39.88-2003\&rfr_id=ori:rid:crossref.org\&rfr_dat=cr_pub\%3dpubmed Accessed October 15, 2019.

7. Liu X, Shah V, Kubilis P, Xu D, Bussing R, Winterstein AG. Psychotropic treatment pattern in Medicaid pediatric patients with concomitant ADHD and ODD/CD. J Atten Disord. 2019;23(2):140-48.

8. Leckman-Westin E, Finnerty M, Scholle SH, et al. Differences in Medicaid antipsychotic medication measures among children with SSI, foster care, and income-based aid. J Manag Care Spec Pharm. 2018;24(3):238-46. Available at: https://www.jmcp.org/doi/10.18553/jmcp.2018.24.3.238.

9. Lohr WD, Creel L, Feygin Y, et al. Psychotropic polypharmacy among children and youth receiving Medicaid, 2012-2015. J Manag Care Spec Pharm. 2018;24(8):736-44. Available at: https://www.jmcp.org/doi/10.18553/ jmcp.2018.24.8.736.

10. Turney K, Wildeman C. Adverse childhood experiences among children placed in and adopted from foster care: evidence from a nationally representative survey. Child Abuse Negl. 2017;64:117-29.

11. DosReis S, Zito JM, Safer DJ, Soeken KL. Mental health services for youths in foster care and disabled youths. Am J Public Health. 2001;91(7):1094-99.

12. McMillen JC, Scott LD, Zima BT, Ollie MT, Munson MR, Spitznagel E. Use of mental health services among older youths in foster care. Psychiatr Serv. 2004;55(7):811-17. Available at: https://ps.psychiatryonline.org/doi/ full/10.1176/appi.ps.55.7.811. Accessed October 15, 2019.

13. Vanderwerker L, Akincigil A, Olfson M, Gerhard T, Neese-Todd S, Crystal S. Foster care, externalizing disorders, and antipsychotic use among Medicaid-enrolled youths. Psychiatr Serv. 2014;65(10):1281-84. Available at: https://ps.psychiatryonline.org/doi/full/10.1176/appi.ps.201300455. Accessed October 15, 2019

14. Crystal S, Mackie T, Fenton MC, et al. Rapid growth of antipsychotic prescriptions for children who are publicly insured has ceased, but concerns remain. Health Aff (Millwood). 2016;35(6):974-82. Available at: https://www. healthaffairs.org/doi/10.1377/hlthaff.2016.0064. Accessed October 15, 2016. 
15. Walkup J; Work Group on Quality Issues. Practice parameter on the use of psychotropic medication in children and adolescents. J Am Acad Child Adolesc Psychiatry. 2009;48(9):961-73. Available at: https://jaacap.org/article/ S0890-8567(09)60156-8/fulltext. Accessed October 15, 2019.

16. Longhofer J, Floersch J, Okpych N. Foster youth and psychotropic treatment: where next? Child Youth Serv Rev. 2011;33(2):395-404.

17. National Committee on Quality Assurance. HEDIS 2018. Vol 2 Technical update. October 2, 2017. Available at: https://www.ncqa.org/wp-content/ uploads/2018/10/20171002_HEDIS_2017_OctoberUpdate.pdf. Accessed October 15, 2019.

18. Patten SB, Waheed W, Bresee L. A review of pharmacoepidemiologic studies of antipsychotic use in children and adolescents. Can J Psychiatry. 2012;57(12):717-21. Available at: https://journals.sagepub.com/ doi/10.1177/070674371205701202. Accessed October 15, 2019.

19. Finnerty M, Neese-Todd S, Bilder S, Olfson M, Crystal S. Best practices: MEDNET: a multistate policy maker-researcher collaboration to improve prescribing practices. Psychiatr Serv. 2014;65(11):1297-99. Available at: https://ps.psychiatryonline.org/doi/full/10.1176/appi.ps.201400343. Accessed October 15, 2019.

20. Wolters Kluwer. Medi-Span Generic Product Identifier (GPI). Available at: https://www.wolterskluwercdi.com/drug-data/gpi/. Accessed October 15, 2019.

21. Andersen R, Newman JF. Societal and individual determinants of medical care utilization in the United States. Milbank Mem Fund Q Health Soc. 1973;51(1):95-124.

22. Douthit N, Kiv S, Dwolatzky T, Biswas S. Exposing some important barriers to health care access in the rural USA. Public Health. 2015;129(6):611-20.

23. U.S. Census Bureau. Housing patterns. Core based statistical areas and related statistical areas. Revised December 7, 2016. Available at: https:// www.census.gov/topics/housing/housing-patterns/about/core-based-statistical-areas.html. Accessed October 24, 2019.

24. Deyo RA, Cherkin DC, Ciol MA. Adapting a clinical comorbidity index for use with ICD-9-CM administrative databases. J Clin Epidemiol. 1992;45(6):613-19.
25. Quan H, Sundararajan V, Halfon P, et al. Coding algorithms for defining comorbidities in ICD-9-CM and ICD-10 administrative data. Med Care. 2005;43(11):1130-39.

26. Knight EK, Mcduffie MJ, Gifford K, Zorc C. Health service utilization of children in Delaware foster care, 2013-2014. Del Med J. 2016;88(2):46-52.

27. Allaire BT, Raghavan R, Brown DS. Morbid obesity and use of second generation antipsychotics among adolescents in foster care: evidence from Medicaid. Child Youth Serv Rev. 2016;67:27-31

28. Reekie J, Hosking SP, Prakash C, Kao KT, Juonala M, Sabin MA. The effect of antidepressants and antipsychotics on weight gain in children and adolescents. Obes Rev. 2015;16(7):566-80

29. Steele JS, Buchi KF. Medical and mental health of children entering the Utah foster care system. Pediatrics. 2008;122(3):e703-09.

30. Oklahoma Health Care Authority. Drug utilization review meeting. Board packet: October 10, 2018. Available at: http://www.okhca.org/about. aspx?id=21258. Accessed October 15, 2019.

31. DosReis S, Yoon Y, Rubin DM, Riddle MA, Noll E, Rothbard A. Antipsychotic treatment among youth in foster care. Pediatrics. 2011;128(6):e1459-el466. Available at: http://www.ocfcpacourts.us/assets/ files/list-10848/file-1364.pdf. Accessed October 15, 2019.

32. Zito JM, Safer DJ, Sai D, et al. Psychotropic medication patterns among youth in foster care. Pediatrics. 2008;121(1):e157-e163.

33. Moran LV, Ongur D, Hsu J, Castro VM, Perlis RH, Schneeweiss S. Psychosis with methylphenidate or amphetamine in patients with ADHD. N Engl J Med. 2019;380(12):1128-18. Available at: https://www.nejm.org/doi/ full/10.1056/NEJMoal813751. Accessed October 15, 2019.

34. Oklahoma Health Care Authority. ADHD and narcolepsy. Second opinion process for children 0-4 years of age and unusual dosing requests. Available at: https://okhca.org/providers.aspx?id=12090\#ADHD. Accessed October 24, 2019 